\title{
Blood Cell In Vitro Cytokine Production in Response to Lipopolysaccharide Stimulation in a Healthy Population: Effects of Age, Sex, and Smoking
}

\author{
Lluis Rodas ${ }^{1}$, Sonia Martínez ${ }^{2,3, * \mathbb{D}}$, Aina Riera-Sampol ${ }^{2,3} \mathbb{D}$, Hannah J. Moir 4 (D) and Pedro Tauler $1,3, * \mathbb{D}$ \\ 1 Research Group on Evidence, Lifestyles and Health, Department of Fundamental Biology and Health Sciences, \\ Research Institute of Health Sciences (IUNICS), University of the Balearic Islands, 07122 Palma, Spain; \\ lluisrodas@hotmail.com \\ 2 Research Group on Evidence, Lifestyles and Health, Department of Nursing and Physiotherapy, \\ Research Institute of Health Sciences (IUNICS), University of the Balearic Islands, 07122 Palma, Spain; \\ ana.riera@uib.es \\ 3 Health Research Institute of the Balearic Islands (IdISBa), 07120 Palma, Spain \\ 4 School of Life Sciences, Pharmacy and Chemistry, Faculty of Science Engineering and Computing, \\ Kingston University London, Penrhyn Road, Kingston upon Thames KT1 2EE, UK; H.Moir@kingston.ac.uk \\ * Correspondence: sonia.martinez@uib.es (S.M.); pedro.tauler@uib.es (P.T.); Tel.: +34-971-172858 (P.T.)
}

check for

updates

Citation: Rodas, L.; Martínez, S.; Riera-Sampol, A.; Moir, H.J.; Tauler, P. Blood Cell In Vitro Cytokine Production in Response to Lipopolysaccharide Stimulation in a Healthy Population: Effects of Age, Sex, and Smoking. Cells 2022, 11, 103. https://doi.org/10.3390/ cells11010103

Academic Editor: Maria Bokarewa

Received: 23 November 2021

Accepted: 27 December 2021

Published: 29 December 2021

Publisher's Note: MDPI stays neutral with regard to jurisdictional claims in published maps and institutional affiliations.

Copyright: (c) 2021 by the authors Licensee MDPI, Basel, Switzerland. This article is an open access article distributed under the terms and conditions of the Creative Commons Attribution (CC BY) license (https:// creativecommons.org/licenses/by/ $4.0 /)$.

\begin{abstract}
Immune system functionality has been commonly assessed by a whole-blood or isolatedcell stimulation assay. The aim of this study was to determine whether cytokine production in whole-blood-stimulated samples is influenced by age, sex, and smoking. A descriptive cross-sectional study in 253 healthy participants aged 18-55 years was conducted. Whole blood samples were stimulated for $24 \mathrm{~h}$ with LPS and concentrations of IL-6, IL-10, and TNF- $\alpha$ were determined in the culture media. Among parameters considered, statistical regression analysis indicated that smoking (change in $\mathrm{R}^{2}=0.064, p<0.001$ ) and sex (change in $\mathrm{R}^{2}=0.070, p<0.001$ ) were the main predictors for IL-10 production, with higher values for women and non-smokers. Age was also found to be a significant predictor (change in $R^{2}=0.021, p<0.001$ ), with higher values for younger ages. Age (change in $R^{2}=0.089, p=0.013$ ) and smoking (change in $R^{2}=0.037, p=0.002$ ) were found to be negative predictors for IL-6 production. Regarding TNF- $\alpha$-stimulated production, age (change in $\mathrm{R}^{2}=0.029, p=0.009$ ) and smoking (change in $\mathrm{R}^{2}=0.022, p=0.022$ ) were found to be negative predictors. Furthermore, sex (change in $\mathrm{R}^{2}=0.016, p=0.045$ ) was found to be a significant predictor, with lower values for women. In conclusion, sex, age, and smoking were found to be independent determinants of stimulated cytokine production. While female sex is associated with higher IL-10 and lower TNF- $\alpha$ production, aging and smoking are associated with lower IL-6, IL-10, and TNF- $\alpha$ production.
\end{abstract}

Keywords: LPS challenge; blood culture; age; sex; smoking; menstrual cycle

\section{Introduction}

The capacity of leukocytes to produce cytokines upon adequate challenge has been considered an interesting question with potential consequences for the entire functional capacity of the immune system [1]. In this regard, immune responsiveness has been commonly assessed by a whole-blood or isolated-cell stimulation assay, which measures the culture concentration of cytokines produced by immune cells upon stimulation with, among others, the Gram-negative stimulus lipopolysaccharide (LPS). [2]. This stimulation assay primarily assesses individuals' cytokine production by monocytes [3], a process reported to be under genetic control [4]. Monocyte-derived cytokines are involved in immune responses such as the activation of $\mathrm{B}$ cells, leading to the production of specific antibodies, the activation of $\mathrm{T}$ cells, leading to cell-mediated immunity, and the enhancement of several 
neutrophil and macrophage/monocyte functions [5]. Consequently, monocyte-derived cytokines play important roles in host defense against bacterial infections [5].

Measurement of LPS-stimulated cytokine production has been used as a model of immune responsiveness in non-infectious diseases [2]. A low stimulated cytokine production has been associated with increased mortality [6], metabolic syndrome and type 2 diabetes [7], lower serum triiodothyronine levels [8], and lower muscle mass and strength [9], all of which are considered as consequences of the aging process. Furthermore, it has been reported that monocytes from depressed patients present an altered response to endotoxin stimulation [10]. However, whether the cytokine production response plays a causal role in the development of these diseases still needs to be determined [2].

The effect of sex on LPS-stimulated cytokine production remains unclear. While some studies have reported a higher stimulated cytokine production in men than in women [2,11-13], others have found no sex differences [14]. In this regard, age has been suggested to be an important factor, as sex differences seem to be higher in young people [2] Regarding age, the influence of aging on the production of cytokines by monocytes has also been investigated, and an impaired ability to produce interleukin (IL)-1 $\beta$ and tumor necrosis factor (TNF)- $\alpha$ with aging has been shown [5,11,15]. However, most of these studies have compared the stimulated cytokine production in elderly (older than 70 years) and in young (around 25-30 years old) populations [5,11]. Whether decreases with aging become significant in the elderly or in earlier ages has not been tested.

The aim of this study was to determine whether the cytokine production in wholeblood-stimulated samples from a young and healthy population is influenced by age, sex, and smoking. In women, the influence of the menstrual cycle was also analyzed.

\section{Materials and Methods}

\subsection{Study Design and Participants}

A descriptive, cross-sectional study was conducted. All participants were informed of the purpose and demands of the study before giving their written consent to participate. The protocol was in accordance with the Declaration of Helsinki for research involving human subjects and was approved by the Balearic Islands Clinical Investigation Ethics Committee (IB 2399/14 PI). All participants were residents in Mallorca (Balearic Islands, Spain). Participants were enrolled after fulfilling all inclusion criteria and presenting none of the exclusion criteria. Participants could be included if they were currently healthy and aged 18-55 years old. Exclusion criteria were common cold, flu or similar diseases, infectious disease or allergic episodes within the previous two weeks, regular alcohol (more than one daily drink in women and two daily drinks in men) or drugs consumption, consumption within the 2 weeks preceding the study of anti-inflammatory medication, and pregnancy. Initially, 255 participants were recruited, but blood could not be obtained from two, and the blood volume taken from three was not enough to perform the stimulation experiences, leading to the final number of 253 participants. Most participants were recruited among students and staff from the University of the Balearic Islands. This allows to ensure that these participants were under similar work-related LPS exposure, one of the factors that could influence cytokine production.

\subsection{Laboratory Visit}

Participants arrived at the laboratory between 08:00 a.m. and 10:00 a.m. following an overnight fast of approximately $12 \mathrm{~h}$. They had been previously informed about the study demands and about the inclusion and exclusion criteria. They had also been instructed to abstain from any moderate-vigorous intensity exercise during the $24 \mathrm{~h}$ before arriving at the laboratory. Smokers were asked to refrain from smoking before the visit (since they woke up). Information about the study was reiterated again to the participants, they completed an inclusion/exclusion criteria questionnaire, and they then signed an informed consent form. Each participant was asked to empty their bladder before body mass, height, and body composition were recorded. Stature was measured to the nearest $0.5 \mathrm{~cm}$ using 
a stadiometer (Seca 220 (CM) Telescopic Height Rod for Column Scales, Seca GmbH, Hamburg, Germany). Body mass was measured to the nearest $0.1 \mathrm{~kg}$ using an electronic scale (Seca 700, Seca GmbH, Hamburg, Germany). Body mass index (BMI) was calculated as weight $(\mathrm{kg})$ divided by height $(\mathrm{m})$ squared $\left(\mathrm{kg} \cdot \mathrm{m}^{-2}\right)$. Smoking habit was ascertained, and participants were classified as smokers or non-smokers. Smokers were asked about the daily number of cigarettes consumed. Female participants were asked about the date of their last menstrual bleed. The period week was ascertained considering this date and a four-week period duration. Participants then sat quietly for $10 \mathrm{~min}$ before a blood sample was taken. Seated venous blood samples were collected in suitable Vacutainer®blood collection tubes with ethylenediaminetetraacetic acid (EDTA) or heparin as an anticoagulant (BD, Madrid, Spain). Blood cell numbers (leukocytes, neutrophils, lymphocytes, and monocytes) were quantified in the EDTA blood sample using an automatic flow cytometer analyzer (ABX Pentra 60, Horiba Medical, Montpellier, France). Blood collected with heparin was used for the blood culture experiences.

\subsection{Blood Culture and LPS Stimulation}

Diluted whole heparin blood (1:3 with culture media, RPMI-1640 Medium, Sigma, St Louis, MO, USA) was incubated into sterile 12-well plates (Sarstedt, Nümbrecht, Germany) with lipopolysaccharide (Escherichia coli serotype 055:B5; Sigma, St Louis, MO, USA; final concentration $10 \mathrm{ng} / \mathrm{mL}$ ), or with the same volume of culture media (spontaneous production) for $24 \mathrm{~h}$ at $37^{\circ} \mathrm{C}$. Immediately after incubation, samples were centrifuged at $1000 \times g$ for $10 \mathrm{~min}$ to obtain the supernatants. Aliquots of these culture supernatants were stored at $-70{ }^{\circ} \mathrm{C}$ until assayed.

\subsection{Cytokine Measurements}

Concentrations of IL-10, IL-6, and TNF- $\alpha$ were determined in the culture supernatants using commercially available enzyme-linked immunosorbent assay kits (Invitrogen, Carlsbad, CA, USA), with a spectrophotometric microplate reader (PowerWavei; BioTek, Winooski, VT, USA). Monocyte numbers were used to normalize cytokine production on a per-cell basis $[1,16]$. Cytokine-stimulated production is reported as the difference between cytokine concentration in stimulated and unstimulated cultures.

\subsection{Statistical Analysis}

Statistical analysis was carried out using IBM SPSS Statistics 22.0 software (IBM, Chicago, IL, USA). All data were tested for normal distribution (Kolmogorov-Smirnov test), and it was found that cytokine-stimulated production values did not follow a normal distribution. The results were expressed as means and standard deviations (SD), or median and interquartile ranges, as specified. Percentages were also used when required. General characteristics of participants were compared using a $t$-test for unpaired data. The MannWhitney $U$ test was used to evaluate differences between sexes and between smoker and non-smoker participants in cytokine-stimulated production. Kruskal-Wallis oneway ANOVA was used to determine the effect of the menstrual cycle week on cytokine production in women, as well as the significance of the changes in cytokine production in participants stratified per age. For this last analysis, five age groups were considered: $18-19,20-29,30-39,40-49$, and 50-55 years old. The existence of significant bivariate correlations between cytokine production (logarithmic transformed), age, and BMI was ascertained by determining Pearson correlation coefficients. Multiple linear regression analysis, using the stepwise procedure, was applied to determine the association between each dependent variable ( $\log 10$ transformed IL-10, IL-6 and TNF- $\alpha$-stimulated production) and independent (age, sex, and smoking status) and control variables (BMI). Statistical significance was accepted at $p<0.05$. 


\section{Results}

\subsection{General Characteristics of Participants in the Study}

Table 1 shows the general characteristics of participants in the study. Higher values for body mass $(p<0.001)$, stature $(p<0.001)$ and BMI $(p<0.001)$ in men than in women were observed. No differences between men and women were found for age $(p=0.534)$, leukocyte $(p=0.681)$, neutrophil $(p=0.363)$, lymphocyte $(p=0.674)$ and monocyte $(p=0.407)$ counts. Among participants in the study, 32 were smokers (11 men and 21 women), with an average daily consumption of $6.6 \pm 10.9$ cigarettes.

Table 1. General characteristics of participants in the study.

\begin{tabular}{ccccc}
\hline Parameter & $\begin{array}{c}\text { All } \\
(\boldsymbol{n}=\mathbf{2 5 3})\end{array}$ & $\begin{array}{c}\text { Men } \\
(\boldsymbol{n}=\mathbf{1 2 0})\end{array}$ & $\begin{array}{c}\text { Women } \\
(\boldsymbol{n}=\mathbf{1 3 3})\end{array}$ & $\boldsymbol{p}$ Value \\
\hline Age (years) & $33.0 \pm 10.9$ & $33.4 \pm 11.0$ & $32.6 \pm 10.9$ & 0.534 \\
\hline Body mass $(\mathrm{kg})$ & $67.0 \pm 13.5$ & $76.3 \pm 11.8$ & $58.6 \pm 8.6$ & $<0.001^{*}$ \\
\hline Stature $(\mathrm{cm})$ & $170.0 \pm 9.6$ & $177.0 \pm 7.1$ & $163.6 \pm 6.4$ & $<0.001^{*}$ \\
\hline BMI $\left(\mathrm{kg} \cdot \mathrm{m}^{-2}\right)$ & $23.1 \pm 3.4$ & $24.3 \pm 3.3$ & $22.0 \pm 3.2$ & $<0.001^{*}$ \\
\hline Leukocytes $\left(10^{3} \cdot \mu \mathrm{L}^{-1}\right)$ & $5.84 \pm 1.38$ & $5.80 \pm 1.18$ & $5.87 \pm 1.55$ & 0.681 \\
\hline Neutrophils $\left(10^{3} \cdot \mu \mathrm{L}^{-1}\right)$ & $3.13 \pm 0.98$ & $3.07 \pm 0.84$ & $3.18 \pm 1.08$ & 0.363 \\
\hline Lymphocytes $\left(10^{3} \cdot \mu \mathrm{L}^{-1}\right)$ & $1.98 \pm 0.60$ & $1.96 \pm 0.59$ & $1.99 \pm 0.60$ & 0.674 \\
\hline Monocytes $\left(10^{3} \cdot \mu \mathrm{L}^{-1}\right)$ & $0.49 \pm 0.41$ & $0.52 \pm 0.37$ & $0.47 \pm 0.44$ & 0.407 \\
\hline Values are expressed as $\mathrm{means}^{*} \mathrm{~S}$.D. ${ }^{*}$ indicates significant differences between men and women $(p<0.05)$.
\end{tabular}

\subsection{Culture Cytokine Production}

No differences per sex, age, or smoking habit were observed for unstimulated IL10, IL-6, and TNF- $\alpha$ production (results not shown). Table 2 shows cytokine production in participants stratified by sex. Higher IL-10 $(p<0.001)$ but lower TNF- $\alpha(p=0.039)$ production were observed in women. No differences between sexes were observed for IL-6 production $(p=0.068)$.

Table 2. Cytokine-stimulated production in participants stratified by sex.

\begin{tabular}{cccc}
\hline Cytokine & $\begin{array}{c}\text { Men } \\
(\boldsymbol{n}=\mathbf{1 2 0})\end{array}$ & $\begin{array}{c}\text { Women } \\
(\boldsymbol{n}=\mathbf{1 3 3})\end{array}$ & $p$ Value \\
\hline IL-10 $\left(\mathrm{pg} \cdot 10^{-3}\right.$ cells $)$ & $20.6(13.5,28.4)$ & $29.1(17.4,42.1)$ & $<0.001^{*}$ \\
\hline IL-6 $\left(\mathrm{pg} \cdot 10^{-3}\right.$ cells $)$ & $372.8(262.7,536.6)$ & $428.8(331.7,586.4)$ & 0.068 \\
\hline TNF- $\alpha\left(\mathrm{pg} \cdot 10^{-3}\right.$ cells $)$ & $56.0(33.9,85.3)$ & $49.4(30.8,69.1)$ & $0.039^{*}$ \\
\hline
\end{tabular}

Values are expressed as median (25th, 75th percentile) and represent the difference between cytokine concentration in stimulated and unstimulated cultures. ${ }^{*}$ indicates significant differences between sexes $(p<0.05)$.

Table 3 shows values for cytokine production in non-smoker and smoker participants. Significant lower productions of IL-10 ( $p<0.001)$, IL-6 $(p=0.003)$ and TNF- $\alpha(p=0.033)$ were observed in smokers.

The analysis of cytokine production stratified by age groups revealed a significant influence of age on IL-6 ( $p=0.001)$ and TNF- $\alpha(p=0.003)$ stimulated production. However, although a decreasing trend in IL-10 production with age was observed, the effect was not significant ( $p=0.240$, Figure 1a). IL-6 production in the group aged 20-29 years was significantly higher than in groups aged 40-49 $(p=0.039)$ and 50-55 $(p=0.002)$ years (Figure 1b). IL-6 production in the group aged 30-39 years was also significantly higher than in the group aged 50-55 years old $(p=0.015)$. TNF- $\alpha$ production in participants aged 20-29 and 30-39 years was higher than in the group aged 50-55 years $(p=0.039$ and 
$p=0.024$, respectively, Figure 1c). Furthermore, TNF- $\alpha$ production was lower in the group aged 18-19 years than in groups aged 20-29 $(p=0.039)$ and 30-39 $(p=0.042)$ years.

Table 3. Cytokine-stimulated production in smoker and non-smoker participants.

\begin{tabular}{cccc}
\hline Cytokine & $\begin{array}{c}\text { Non-smokers } \\
(\boldsymbol{n}=\mathbf{2 2 1})\end{array}$ & $\begin{array}{c}\text { Smokers } \\
(\boldsymbol{n}=\mathbf{3 2})\end{array}$ & $\boldsymbol{p}$ Value \\
\hline IL-10 $\left(\mathrm{pg} \cdot 10^{-3}\right.$ cells $)$ & $25.0(16.3,35.7)$ & $14.3(10.5,22.6)$ & $<0.001^{*}$ \\
\hline IL-6 $\left(\mathrm{pg} \cdot 10^{-3}\right.$ cells $)$ & $397.8(299.0,562.0)$ & $288.3(223.2,445.4)$ & $0.003 *$ \\
\hline TNF- $\alpha\left(\mathrm{pg} \cdot 10^{-3}\right.$ cells $)$ & $53.0(34.1,81.5)$ & $42.1(26.8,60.0)$ & $0.033^{*}$ \\
\hline Values are expressed as median $(25$ h $; 75$ th percentile $)$ & and represent the difference between cytokine con-
\end{tabular}

Values are expressed as median (25th; 75th percentile) and represent the difference between cytokine concentration in stimulated and unstimulated cultures. ${ }^{*}$ indicates significant differences between smokers and non-smokers $(p<0.05)$.

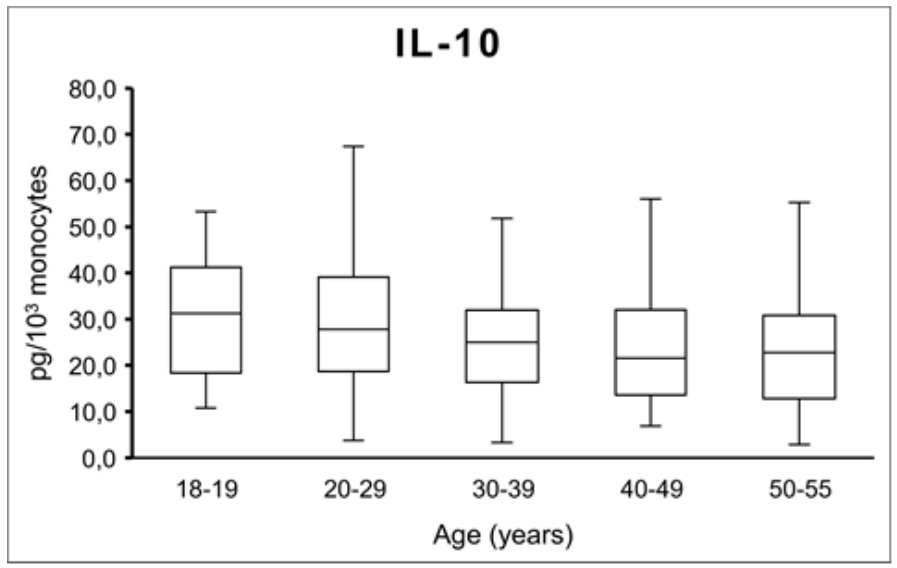

(a)

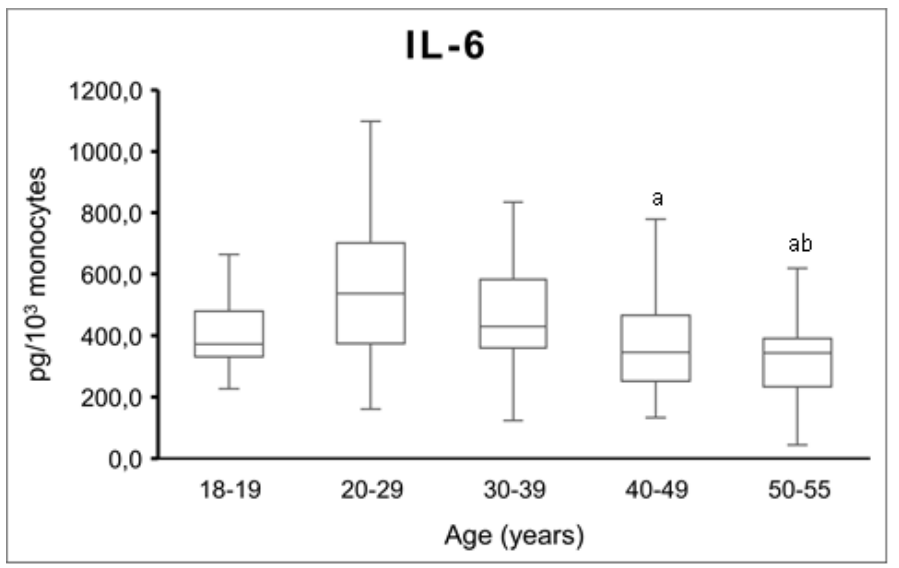

(b)

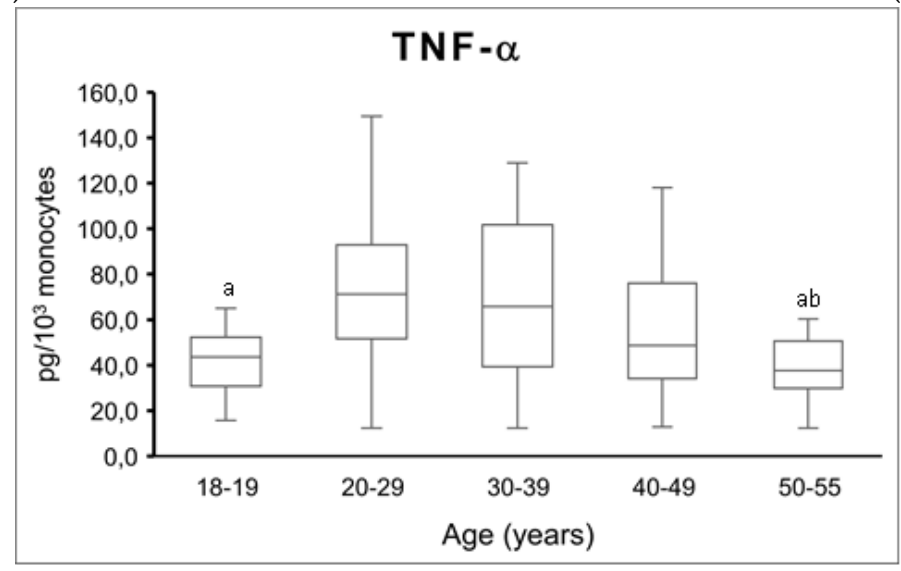

(c)

Figure 1. IL-10 (a), IL-6 (b), and TNF- $\alpha$ (c) stimulated production stratified by age groups. Median, 25th, 75th percentile, and lowest and highest values for cytokine production are shown. Age 18-19, $n$ = 22; age 20-29, $n=82$; age 30-39, $n=63$; age 40-49, $n=51$; age 50-55, $n=35$. "a" indicates significant differences vs. 20-29 y group, " $b$ ” indicates significant differences vs. 30-39 y group $(p<0.05)$.

\subsection{Correlations between Cytokine-Stimulated Production, Age, and BMI}

When correlations between cytokine production (logarithmic transformations) and continuous dependent variables (age and BMI) were analyzed, it was observed that IL-10 ( $\mathrm{r}=-0.267$, $p=0.021)$ and IL-6 $(r=-0.267, p<0.001)$ production were significantly correlated with age. Furthermore, IL-10 production was correlated with BMI $(r=-0.159, p=0.012)$. 


\subsection{Linear Regression Analysis for IL-6-, IL-10-, and TNF- $\alpha$-Stimulated Production}

Table 4 shows the results of the regression analysis for IL-10 production (significant predictors). Model 1 includes smoking as the significant predictor (change in $\mathrm{R}^{2}=0.064$, $p<0.001)$, with higher IL-10-stimulated production for non-smokers. Model 2 incorporates sex as a significant predictor (change in $R^{2}=0.070, p<0.001$ ), increasing $R^{2}$ adjusted value from 0.064 to 0.134 , and with higher IL-10 production for women. Finally, model 3 includes age as a significant negative predictor (change in $\mathrm{R}^{2}=0.021, p=0.013$ ), leading to a final $R^{2}$ adjusted value of 0.145 , and with IL-10-simulated production decreasing with age $(\beta=-0.145)$.

Table 4. Regression models for IL-10-stimulated production.

\begin{tabular}{|c|c|c|c|c|c|c|c|c|c|}
\hline & B & $\beta$ & $95 \% \mathrm{CI}$ & $\mathbf{t}$ & $p$ Value & $\mathbf{R}^{2}$ & Adjusted $\mathrm{R}^{2}$ & $\begin{array}{l}p \text { Value } \\
\text { (ANOVA) }\end{array}$ & $\mathbf{R}^{2}$ Change \\
\hline Model 1 & & & & & & 0.064 & 0.060 & $<0.001$ * & 0.064 \\
\hline Smoking & -0.196 & -0.253 & $(-0.289,-0.103)$ & -4.148 & $<0.001 *$ & & & & \\
\hline Model 2 & & & & & & 0.134 & 0.127 & $<0.001$ * & 0.070 \\
\hline Smoking & -0.216 & -0.280 & $(-0.306,-0.126)$ & -4.731 & $<0.001 *$ & & & & \\
\hline Sex & 0.137 & 0.266 & $(0.077,0.197)$ & 4.504 & $<0.001$ * & & & & \\
\hline Model 3 & & & & & & 0.155 & 0.145 & $<0.001$ * & 0.021 \\
\hline Smoking & -0.220 & -0.285 & $(-0.309,-0.131)$ & -4.859 & $<0.001$ * & & & & \\
\hline Sex & 0.134 & 0.261 & $(0.075,0.194)$ & 4.459 & $<0.001 *$ & & & & \\
\hline \multirow[t]{2}{*}{ Age } & -0.003 & -0.145 & $(-0.006,-0.001)$ & -2.490 & 0.013 * & & & & \\
\hline & & & $\begin{array}{l}\text { Logarithmic transform } \\
\text { beta coefficient; * indica } \\
\text { indicates lower values } \\
\text { indicates higher values }\end{array}$ & $\begin{array}{l}\text { ion of IL-1 } \\
\text { s statistica } \\
\text { IL-10-stir } \\
\text { n women }\end{array}$ & $\begin{array}{l}\text { stimulated } \mathrm{p} \\
\text { significant } \\
\text { lated produ } \\
\text { an in men. }\end{array}$ & $\begin{array}{l}\text { uction w } \\
\text { dictors a } \\
\text { on in sme }\end{array}$ & $\begin{array}{l}\text { used. } n=253 . \mathrm{B}: \mathrm{r} \\
\text { models }(p<0.05) \text {. } \\
\text { rs than in non-sm }\end{array}$ & $\begin{array}{l}\text { ession coefficie } \\
\text { e negative coe } \\
\text { ers. The positiv }\end{array}$ & $\begin{array}{l}\beta \text { : standardizec } \\
\text { ient for smokin } \\
\text { oefficient for se }\end{array}$ \\
\hline
\end{tabular}

Table 5 shows the linear multiple regression models for IL-6- and TNF- $\alpha$-stimulated production (significant predictors). As it is shown in the previous section, age was not linearly associated with IL- 6 and TNF- $\alpha$ production, which supposes one of the assumptions for a variable to be included in the linear regression analysis, mainly due to values observed for participants aged 18 and 19 years old. Therefore, only participants aged 20 and older were included in this linear regression analysis. Among factors considered, age was found to be the main significant predictor (change in $\mathrm{R}^{2}=0.089, p<0.001$ ) for IL-6 production (model 1). Within participants considered in this analysis, IL-6-stimulated production decreased with age $(\beta=-0.298)$. In addition, model 2 includes smoking as a significant predictor (change in $\mathrm{R}^{2}=0.037, p=0.002$ ), increasing adjusted $\mathrm{R}^{2}$ from 0.085 to 0.118 , and with higher productions for non-smokers. In a similar way, model 1 for TNF- $\alpha$ production included age as the significant, and negative, predictor $(\beta=-0.170$, change in $\mathrm{R}^{2}=0.029, p=0.009$ ). Model 2 for TNF- $\alpha$ production also includes smoking as a significant predictor (change in $R^{2}=0.022, p=0.022$ ), increasing adjusted $R^{2}$ from 0.025 to 0.042 . Model 3 for TNF- $\alpha$-stimulated production considers sex as the last significant predictor (change in $\left.R^{2}=0.016, p=0.045\right)$, leading to a final adjusted $R^{2}$ value of 0.067 .

\subsection{Effects of the Menstrual Cycle on the Cytokine-Stimulated Production}

Table 6 shows the cytokine production in women stratified per menstrual cycle week. A significant effect of the menstrual cycle on IL-10-stimulated production was observed $(p=0.035)$, with higher production in the second than in the third week $(p=0.039)$. No effects were observed for IL-6 $(p=0.681)$ and TNF- $\alpha(p=0.383)$ production. 
Table 5. Regression models for IL-6- and TNF- $\alpha$-stimulated production.

\begin{tabular}{|c|c|c|c|c|c|c|c|c|c|}
\hline & B & $\beta$ & $95 \% \mathrm{CI}$ & $\mathbf{t}$ & $p$ Value & $\mathbf{R}^{2}$ & Adjusted $R^{2}$ & $\begin{array}{c}p \text { Value } \\
\text { (ANOVA) }\end{array}$ & $\mathbf{R}^{2}$ Change \\
\hline \multicolumn{10}{|l|}{ IL-6 } \\
\hline Model 1 & & & & & & 0.089 & 0.085 & $<0.001 *$ & 0.089 \\
\hline Age & -0.006 & -0.298 & $(-0.009,-0.004)$ & -4.744 & $<0.001 *$ & & & & \\
\hline Model 2 & & & & & & 0.126 & 0.118 & $<0.001 *$ & 0.037 \\
\hline Age & -0.006 & -0.311 & $(-0.009,-0.004)$ & -5.032 & $<0.001 *$ & & & & \\
\hline Smoking & -0.123 & -0.193 & $(-0.201,-0.045)$ & -3.119 & $0.002 *$ & & & & \\
\hline \multicolumn{10}{|l|}{ TNF- $\alpha$} \\
\hline Model 1 & & & & & & 0.029 & 0.025 & 0.009 * & 0.029 \\
\hline Age & -0.005 & -0.170 & $(-0.009,-0.001)$ & -2.623 & $0.009 *$ & & & & \\
\hline Model 2 & & & & & & 0.051 & 0.042 & $0.002 *$ & 0.022 \\
\hline Age & -0.005 & -0.180 & $(-0.009,-0.002)$ & -2.796 & $0.006^{*}$ & & & & \\
\hline Smoking & -0.137 & -0.148 & $(-0.254,-0.020)$ & -2.309 & $0.022 *$ & & & & \\
\hline Model 3 & & & & & & 0.067 & 0.055 & 0.001 * & 0.016 \\
\hline Age & -0.005 & -0.181 & $(-0.009,-0.002)$ & -2.836 & $0.005 *$ & & & & \\
\hline Smoking & -0.137 & -0.132 & $(-0.239,-0.005)$ & -2.309 & 0.041 * & & & & \\
\hline Sex & -0.081 & -0.129 & $(-0.160,-0.002)$ & -3.063 & $0.045^{*}$ & & & & \\
\hline
\end{tabular}

Table 6. Cytokine-stimulated production Cytokine production in women stratified per menstrual cycle week.

\begin{tabular}{|c|c|c|c|c|c|}
\hline Cytokine & $\begin{array}{l}\text { Week } 1 \\
(n=37)\end{array}$ & $\begin{array}{l}\text { Week } 2 \\
(n=31)\end{array}$ & $\begin{array}{l}\text { Week } 3 \\
(n=28)\end{array}$ & $\begin{array}{l}\text { Week } 4 \\
(n=37)\end{array}$ & $p$ Value \\
\hline $\begin{array}{l}\text { IL-10 (pg.10-10 } \\
\text { cells) }\end{array}$ & $\begin{array}{c}31.3 \\
(20.8 ; 44.6)\end{array}$ & $\begin{array}{c}42.3 \\
(29.2 ; 51.4) \mathrm{a}\end{array}$ & $\begin{array}{c}25.9 \\
(19.0 ; 38.1)\end{array}$ & $\begin{array}{c}31.3 \\
(14.7 ; 41.4)\end{array}$ & $0.035 *$ \\
\hline $\begin{array}{l}\text { IL-6 (pg.10-3 } \\
\text { cells) }\end{array}$ & $\begin{array}{c}462.8 \\
(346.3 ; 610.6)\end{array}$ & $\begin{array}{c}414.7 \\
(349.1 ; 569.5)\end{array}$ & $\begin{array}{c}470.8 \\
(354.9 ; 709.4)\end{array}$ & $\begin{array}{c}448.8 \\
(342.1 ; 618.9)\end{array}$ & 0.681 \\
\hline $\begin{array}{c}\mathrm{TNF}-\alpha\left(\mathrm{pg} \cdot 10^{-3}\right. \\
\text { cells) }\end{array}$ & $\begin{array}{c}52.1 \\
(29.3 ; 85.7)\end{array}$ & $\begin{array}{c}43.4 \\
(31.8 ; 58.4)\end{array}$ & $\begin{array}{c}57.7 \\
(39.6 ; 80.7)\end{array}$ & $\begin{array}{c}51.3 \\
(32.3 ; 78.7)\end{array}$ & 0.383 \\
\hline
\end{tabular}

Values are expressed as median (25th; 75 th percentile). $n=133 . p$-adjusted values are reported. ${ }^{*}$ indicates statistically significant differences where "a" indicates significant differences between the third and the second week $(p<0.05)$.

\section{Discussion}

The main findings of the present study were that women showed lower production of the pro-inflammatory cytokine TNF- $\alpha$ and higher production of the anti-inflammatory cytokine IL-10 than men. Furthermore, a general decrease in cytokine-stimulated production with aging, as well as lower values in smokers than in non-smokers, were observed.

Sex, age, and smoking have been found as mutually independent determinants of stimulated cytokine production, with a consistent contribution as the regression coefficients of the regression analysis hardly change when another determinant was added to the model (Tables 4 and 5). Factors considered in the present study (sex, age, and smoking) could explain only a limited fraction of all interindividual variation in cytokine responses. Therefore, additional factors must be considered in future studies to improve the analysis of 
the cytokine response upon stimulation. However, it should be considered that stimulated cytokine production is under tight genetic control, which could account for over $50 \%$ of this variability [4].

Regarding age, a decrease in the production of the cytokines with aging could be considered as the main general observation. In accordance with the decreased stimulated production observed in the present study, others have reported decreased LPS-induced production of TNF- $\alpha$ by isolated monocytes from elderly (79 years old) compared with young (33 years old) humans [5] and also reduced production by stimulated whole blood in participants aged 81 years with respect to participants aged 19-30 years [11]. It is noteworthy that in the present study, decreased production of the pro-inflammatory cytokine TNF- $\alpha[5,11]$, but also of IL-6 [5], was observed for participants aged around 50 years old, while most of the previous studies reported such decreased levels for older ages. Although a previous study [11] did not find a decrease in IL-6-stimulated production, it was pointed out that IL-6 production showed a strong linear correlation with the decreased TNF- $\alpha$ production. The significance of this decreased production is not clear. As it has been previously suggested, the lower production of these cytokines in the elderly may provide an explanation for them becoming more susceptible to infections and having a poor clinical outcome [5]. Furthermore, this decreased production may be of special importance in elderly humans with underlying health disorders, whereas the clinical relevance is questionable in healthy elderly [11]. It has been suggested that ex vivo LPS-stimulated leukocytes TNF- $\alpha$ release could be considered a biomarker of monocytic immune capacity and reflective of global immune competence, the persistent reduction being predictive of adverse outcomes, and its restoration as an indicator of clinical improvement [16-19].

Regarding changes in stimulated cytokine production with aging, it is noteworthy that TNF- $\alpha$ production was lower in participants aged 18-19 years old than in the ones aged 20-29 years old, a pattern also observed for IL-6 but with non-significant differences. In this regard, as it has been indicated in the Section 3, participants aged 18-19 years were excluded from the regression analysis because when these participants were considered age was not simply linearly associated with cytokine (IL-6 and TNF- $\alpha$ )-stimulated production. However, it should be noted that even after including all participants in the regression analysis, age remained a significant predictor for both IL- 6 and TNF- $\alpha$ production (results not shown). However, the models explained a lower percentage of interindividual variation $\left(\mathrm{R}^{2}\right.$ values: IL-6: 0.105 vs. 0.126 ; TNF- $\alpha$ : 0.032 vs. 0.067 ). These lower values could be due, at least in part, to the lack of a complete linear fitting between age and stimulated cytokine production described above. Therefore, while we can conclude that aging induced lower cytokinestimulated production, and it seems that for the pro-inflammatory cytokines the pattern of change in the younger participants is different. The lower pro-inflammatory cytokine production in the youngest participants could be related to incomplete development of the immune system, as it has been suggested that this is completed during the second decade of life $[20,21]$. In fact, results from the present study suggest that the highest pro-inflammatory cytokine production was reached at 20-29 years old. However, more studies should be performed to further clarify this question.

Sex differences in cytokine-stimulated production were previously reviewed in a study with results from 15 populations [2]. This study concluded that sex differences in cytokine-stimulated production disappear when results were normalized using the monocyte number, except for higher production of IL-10 in women than in men. In agreement with this last observation, a higher stimulated IL-10 production was found in women than in men in the present study (Table 2). Actually, sex was found as a significant predictor for IL-10-stimulated production (Table 4). The significance of this difference is unknown. It has been suggested that an association with reproductive success could exist, as it has been described that reproductive success could be dependent on a strong IL-10 production response at the fetal-maternal interface [22]. However, a previous study in physically active participants reported that a high IL-10-stimulated production was a risk factor for the development of upper respiratory tract infection (URTI) [23]. This effect was attributed 
to an inhibitory role of IL-10 on Th1 antiviral actions rather than to the inhibition of proinflammatory cytokine production [23]. Along the same lines, it has been reported that high IL-10 responders had wheezing symptoms more often than low IL-10 responders [24]. Furthermore, a higher pro-inflammatory cytokine and a lower anti-inflammatory production response upon stimulation with LPS have been associated with survival from meningococcal infection [25], a lower incidence of systemic lupus erythematosus [26], and less severe progression of multiple sclerosis [27]. Within the healthy participants in the present study, in addition to higher IL-10 production, lower TNF- $\alpha$ production in women was observed, which is in agreement with previous observations [24,28]. This decreased value in women has, in general, been attributed to the influence of sex hormones, mainly estrogens [28]. The lower TNF- $\alpha$ production in women than in men could be one of the factors causing the lower incidence of sepsis among women [29].

Chronic smoking has been shown to induce an important impairment in the host defense, with nicotine playing an important role [30]. However, it is striking that a potential therapeutic anti-inflammatory role has been attributed to nicotine, preventing some inflammatory and neurodegenerative diseases [30]. Regarding cytokine-stimulated production, it has been reported that the suppressive effect of smoking is restricted to the lungs [31]. In the present study, decreased stimulated productions of the three cytokines tested were found. The decreased IL-10 production could be attributed to nicotine because, in different cellular models, a suppressive effect of nicotine exposure on the IL-10-stimulated production has been found [32,33]. It is noteworthy that, in the present study, lower monocyte numbers were found in smokers (results not shown), which could have influenced the results observed. The decrease in IL- 6 and TNF- $\alpha$ production could be in agreement with previous results reporting decreased pro-inflammatory production in stimulated alveolar macrophages [31]. However, complete molecular mechanisms leading to this impaired immune function in smokers remain to be fully elucidated.

Previous studies have reported that monocytes produce lower levels of pro-inflammatory cytokines both after LPS stimulation [34] and spontaneously [35] in the presence of high concentrations of female hormones. In the present study, within female participants, differences were found in the stimulated production of IL-10 during the menstrual cycle, with higher production in the second than in the third week (Table 6). These results could be explained by changes in the concentration of estrogen during the menstrual cycle. In this regard, while the third week is characterized by low concentrations of estrogen, with a pro-inflammatory effect, the second week is characterized by higher levels of estrogen, with potent anti-inflammatory effects [36,37]. In fact, despite being non-significant, slightly increased production of IL- 6 and TNF- $\alpha$ were observed in the present study during the third week, which could be a consequence of the pro-inflammatory characteristics of this week. However, it is noteworthy that a previous study, using a different approach, through which 12 cycles in only 5 women were analyzed, did not find any change in the cytokine-stimulated production during the menstrual cycle [38].

This study presents some limitations that should be acknowledged. The production of only two pro-inflammatory and one anti-inflammatory cytokine was measured. This, together with the observational nature of the study, could hamper, at least in part, a conclusive and comprehensive interpretation of the effects of different factors analyzed. Furthermore, participants in the study were recruited only in Mallorca, and therefore, the results of the study could not be generalized elsewhere. The low number of smokers considered, together with the lack of additional measurements related to mechanisms involved, such as nicotine or cotinine levels, did not allow proper conclusions to be drawn regarding the effect of smoking. Stimulation for $24 \mathrm{~h}$ was chosen to optimize the production of IL-10, as it has been reported that stimulated IL-10 production is secondary to the release of proinflammatory cytokines [39]. However, this may have resulted in missing differences in IL- 6 and TNF- $\alpha$ production, which are typically induced earlier, increasing immediately after incubation and peaking $4 \mathrm{~h}$ after [39]. Furthermore, it should also be considered that while other studies used isolated monocytes, in this study, LPS stimulation of whole-blood cultures 
was used. It has been considered that this model probably comes closest to the natural environment, avoiding artifacts from preparation and allowing natural interactions [3]. Regarding the analysis of age influence, it should be noted that age groups considered in the analysis of cytokine production were arbitrarily chosen, and this distribution resulted in different numbers of participants in each age group, with a higher number of participants aged 20-29 years. Hormone levels were not measured in women to find out the effects of hormone concentrations on cytokine production. Therefore, an objective association between hormone levels and cytokine production could not be established.

\section{Conclusions}

Sex, age, and smoking were found to be independent determinants of stimulated cytokine production. While the female sex was associated with higher IL-10 and lower TNF- $\alpha$ production, aging was associated with lower levels of stimulated IL-6, TNF- $\alpha$, and IL-10 production. Regarding changes with age, it is noteworthy that significantly decreased values for IL- 6 and TNF- $\alpha$ production were observed in individuals aged around 50 years old. Therefore, when LPS-stimulated cytokine production is analyzed in patients with diseases, the effect of age, and also differences between sexes, should be considered as confounding factors.

Author Contributions: Conceptualization, P.T.; methodology, P.T., S.M., A.R.-S. and L.R.; formal analysis, P.T. and H.J.M.; investigation, L.R., S.M., A.R.-S. and P.T.; resources, P.T. and S.M., data curation, L.R. and P.T.; writing-original draft preparation, L.R.; writing-review and editing, P.T., A.R.-S., H.J.M. and S.M.; visualization, L.R.; supervision, P.T. and S.M.; project Administration, P.T. and S.M.; funding acquisition, P.T. and S.M. All authors have read and agreed to the published version of the manuscript.

Funding: This research was funded by the Ministerio de Economía, Industria y Competitividad (MINECO), the Agencia Estatal de Investigación (AEI) and the European Regional Development Funds (ERDF), project DEP2013-45966-p (MINECO/AEI/ERDF, EU).

Institutional Review Board Statement: The study was conducted according to the guidelines of the Declaration of Helsinki and approved by the Balearic Islands Clinical Investigation Ethics Committee (IB 2399/14 PI).

Informed Consent Statement: Informed consent was obtained from all subjects involved in the study.

Data Availability Statement: The data presented in this study are available on request from the corresponding author.

Acknowledgments: The authors would like to thank all the participants in the study.

Conflicts of Interest: The authors declare no conflict of interest. The funders had no role in the design of the study; in the collection, analyses, or interpretation of data; in the writing of the manuscript, or in the decision to publish the results.

\section{References}

1. Abbasi, A.; Fehrenbach, E.; Hauth, M.; Walter, M.; Hudemann, J.; Wank, V.; Niess, A.M.; Northoff, H. Changes in spontaneous and lps-induced ex vivo cytokine production and mrna expression in male and female athletes following prolonged exhaustive exercise. Exerc. Immunol. Rev. 2013, 19, 8-28. [PubMed]

2. $\quad$ Beenakker, K.G.M.; Westendorp, R.G.J.; De Craen, A.J.M.; Chen, S.; Raz, Y.; Ballieux, B.E.P.B.; Nelissen, R.G.H.H.; Later, A.F.L.; Huizinga, T.W.; Slagboom, P.E.; et al. Men Have a Stronger Monocyte-Derived Cytokine Production Response upon Stimulation with the Gram-Negative Stimulus Lipopolysaccharide than Women: A Pooled Analysis Including 15 Study Populations. J. Innate Immun. 2020, 12, 142-153. [CrossRef]

3. Damsgaard, C.T.; Lauritzen, L.; Calder, P.C.; Kjær, T.M.R.; Frøkiær, H. Whole-blood culture is a valid low-cost method to measure monocytic cytokines-A comparison of cytokine production in cultures of human whole-blood, mononuclear cells and monocytes. J. Immunol. Methods 2009, 340, 95-101. [CrossRef] [PubMed]

4. De Craen, A.J.M.; Posthuma, D.; Remarque, E.J.; van den Biggelaar, A.H.J.; Westendorp, R.G.J.; Boomsma, D.I. Heritability estimates of innate immunity: An extended twin study. Genes Immun. 2005, 6, 167-170. [CrossRef] 
5. Gon, Y.; Hashimoto, S.; Hayashi, S.; Koura, T.; Matsumoto, K.; Horie, T. Lower serum concentrations of cytokines in elderly patients with pneumonia and the impaired production of cytokines by peripheral blood monocytes in the elderly. Clin. Exp. Immunol. 1996, 106, 120-126.

6. Wijsman, C.A.; Maier, A.B.; De Craen, A.J.M.; Van Den Biggelaar, A.H.J.; Westendorp, R.G.J. An unopposed proinflammatory response is beneficial for survival in the oldest old. Results of the Leiden 85-plus study. J. Gerontol. Ser. A Biol. Sci. Med. Sci. 2011, 66 A, 393-399. [CrossRef]

7. Van Exel, E.; Gussekloo, J.; De Craen, A.J.M.; Frölich, M.; Van Der Wiel, A.B.; Westendorp, R.G.J. Low production capacity of interleukin-10 associates with the metabolic syndrome and type 2 diabetes: The Leiden 85-plus study. Diabetes 2002, 51, 1088-1092. [CrossRef]

8. Rozing, M.P.; Westendorp, R.G.J.; Maier, A.B.; Wijsman, C.A.; Frölich, M.; De Craen, A.J.M.; Van Heemst, D. Serum triiodothyronine levels and inflammatory cytokine production capacity. Age 2012, 34, 195-201. [CrossRef]

9. Beenakker, K.G.M.; Westendorp, R.G.J.; De Craen, A.J.M.; Slagboom, P.E.; Van Heemst, D.; Maier, A.B. Pro-inflammatory capacity of classically activated monocytes relates positively to muscle mass and strength. Aging Cell 2013, 12, 682-689. [CrossRef] [PubMed]

10. Lisi, L.; Camardese, G.; Treglia, M.; Tringali, G.; Carrozza, C.; Janiri, L.; Dello Russo, C.; Navarra, P. Monocytes from Depressed Patients Display an Altered Pattern of Response to Endotoxin Challenge. PLoS ONE 2013, 8, e52585.

11. Bruunsgaard, H.; Pedersen, A.N.; Schroll, M.; Skinhoj, P.; Pedersen, B.K. Impaired production of proinflammatory cytokines in response to lipopolysaccharide (LPS) stimulation in elderly humans. Clin Exp. Immunol. 1999, 118, 235-241. [CrossRef] [PubMed]

12. Auger, G.; Corvec, S.; Roquilly, A.; Segain, J.P.; Lepelletier, D.; Reynaud, A.; Asehnoune, K. Escherichia coli-induced productions of pro-inflammatory cytokines are regulated by MAP kinases and G-protein but not by Akt: Relationship with phylogenetic groups and resistance patterns. Cytokine 2011, 56, 290-297. [CrossRef] [PubMed]

13. Heesen, M.; Bloemeke, B.; Heussen, N.; Kunz, D. Can the interleukin- 6 response to endotoxin be predicted? Studies of the influence of a promoter polymorphism of the interleukin-6 gene, gender, the density of the endotoxin receptor CD14, and inflammatory cytokines. Crit. Care Med. 2002, 30, 664-669. [CrossRef]

14. Lynch, E.A.; Dinarello, C.A.; Cannon, J.G. Gender differences in IL-1 $\alpha$, IL-1 $\beta$, and IL-1 receptor antagonist secretion from mononuclear cells and urinary excretion. J. Immunol. 1994, 153, 300-306. [PubMed]

15. Ter Horst, R.; Jaeger, M.; Smeekens, S.P.; Oosting, M.; Swertz, M.A.; Li, Y.; Kumar, V.; Diavatopoulos, D.A.; Jansen, A.F.M.; Lemmers, H.; et al. Host and Environmental Factors Influencing Individual Human Cytokine Responses. Cell 2016, 167, 1111-1124. [CrossRef]

16. Segre, E.; Fullerton, J.N. Stimulated whole blood cytokine release as a biomarker of immunosuppression in the critically ill: The need for a standardized methodology. Shock 2016, 45, 490-494. [CrossRef]

17. Drewry, A.M.; Ablordeppey, E.A.; Murray, E.T.; Beiter, E.R.; Walton, A.H.; Hall, M.W.; Hotchkiss, R.S. Comparison of monocyte human leukocyte antigen-DR expression and stimulated tumor necrosis factor alpha production as outcome predictors in severe sepsis: A prospective observational study. Crit. Care 2016, 20, 334. [CrossRef]

18. Hall, M.W.; Knatz, N.L.; Vetterly, C.; Tomarello, S.; Wewers, M.D.; Volk, H.D.; Carcillo, J.A. Immunoparalysis and nosocomial infection in children with multiple organ dysfunction syndrome. Intensive Care Med. 2011, 37, 525-532. [CrossRef]

19. Döcke, W.D.; Randow, F.; Syrbe, U.; Krausch, D.; Asadullah, K.; Reinke, P.; Volk, H.D.; Kox, W. Monocyte deactivation in septic patients: Restoration by IFN- $\gamma$ treatment. Nat. Med. 1997, 3, 678-681. [CrossRef]

20. Simon, A.K.; Hollander, G.A.; McMichael, A. Evolution of the immune system in humans from infancy to old age. Proc. R. Soc. B Biol. Sci. 2015, 282, 20143085. [CrossRef]

21. Martínez de Toda, I.; Maté, I.; Vida, C.; Cruces, J.; De la Fuente, M. Immune function parameters as markers of biological age and predictors of longevity. Aging 2016, 8, 3110-3119. [CrossRef]

22. Westendorp, R.G.J.; Van Dunne, F.M.; Kirkwood, T.B.L.; Helmerhorst, F.M.; Huizinga, T.W.J. Optimizing human fertility and survival. Nat. Med. 2001, 7, 873. [CrossRef]

23. Gleeson, M.; Bishop, N.; Oliveira, M.; McCauley, T.; Tauler, P.; Muhamad, A.S. Respiratory infection risk in athletes: Association with antigen-stimulated IL-10 production and salivary IgA secretion. Scand. J. Med. Sci. Sports 2012, 22, 410-417. [CrossRef] [PubMed]

24. Smit, L.A.M.; Heederik, D.; Doekes, G.; Krop, E.J.M.; Rijkers, G.T.; Wouters, I.M. Ex vivo cytokine release reflects sensitivity to occupational endotoxin exposure. Eur. Respir. J. 2009, 34, 795-802. [CrossRef]

25. Westendorp, R.G.J.; Langermans, J.A.M.; Huizinga, T.W.J.; Elouali, A.H.; Verweij, C.L.; Boomsma, D.I.; Vandenbrouke, J.P. Genetic influence on cytokine production and fatal meningococcal disease. Lancet 1997, 349, 170-173. [CrossRef]

26. Van der Linden, M.W.; Westendorp, R.G.J.; Sturk, A.; Bergman, W.; Huizinga, T.W.J. High interleukin-10 production in first-degree relatives of patients with generalized but not cutaneous lupus erythematosus. J. Investig. Med. 2000, 48, 327-334. [PubMed]

27. De Jong, B.A.; Huizinga, T.W.J.; Bollen, E.L.E.M.; Uitdehaag, B.M.J.; Bosma, G.P.T.; Van Buchem, M.A.; Remarque, E.J.; Burgmans, A.C.S.; Kalkers, N.F.; Polman, C.H.; et al. Production of IL-1 $\beta$ and IL-1Ra as risk factors for susceptibility and progression of relapse-onset multiple sclerosis. J. Neuroimmunol. 2002, 126, 172-179. [CrossRef]

28. Von Aulock, S.; Deininger, S.; Draing, C.; Gueinzius, K.; Dehus, O.; Hermann, C. Gender difference in cytokine secretion on immune stimulation with LPS and LTA. J. Interf. Cytokine Res. 2006, 26, 887-892. [CrossRef] 
29. Dombrovskiy, V.Y.; Martin, A.A.; Sunderram, J.; Paz, H.L. Rapid increase in hospitalization and mortality rates for severe sepsis in the United States: A trend analysis from 1993 to 2003. Crit. Care Med. 2007, 35, 1244-1250. [CrossRef]

30. Sopori, M. Effects of cigarette smoke on the immune system. Nat. Rev. Immunol. 2002, 2, 372-377. [CrossRef]

31. Chen, H.; Cowan, M.J.; Hasday, J.D.; Vogel, S.N.; Medvedev, A.E. Tobacco Smoking Inhibits Expression of Proinflammatory Cytokines and Activation of IL-1R-Associated Kinase, p38, and NF-кB in Alveolar Macrophages Stimulated with TLR2 and TLR4 Agonists. J. Immunol. 2007, 179, 6097-6106. [CrossRef] [PubMed]

32. Van Zyl-Smit, R.N.; Binder, A.; Meldau, R.; Semple, P.L.; Evans, A.; Smith, P.; Bateman, E.D.; Dheda, K. Cigarette smoke impairs cytokine responses and BCG containment in alveolar macrophages. Thorax 2014, 69, 363-370. [CrossRef] [PubMed]

33. Matsunaga, K.; Klein, T.W.; Friedman, H.; Yamamoto, Y. Involvement of Nicotinic Acetylcholine Receptors in Suppression of Antimicrobial Activity and Cytokine Responses of Alveolar Macrophages to Legionella pneumophila Infection by Nicotine. J. Immunol. 2001, 167, 6518-6524. [CrossRef]

34. Li, Z.G.; Danis, V.A.; Brooks, P.M. Effect of gonadal steroids on the production of IL-1 and IL-6 blood mononuclear cells in vitro. Clin. Exp. Rheumatol. 1993, 11, 157-162. [PubMed]

35. Pacifici, R.; Brown, C.; Puscheck, E.; Friedrich, E.; Slatopolsky, E.; Maggio, D.; Mccracken, R.; Avioli, L.V. Effect of surgical menopause and estrogen replacement on cytokine release from human blood mononuclear cells. Proc. Natl. Acad. Sci. USA 1991, 88, 5134-5138. [CrossRef]

36. Allen, A.M.; McRae-Clark, A.L.; Carlson, S.; Saladin, M.E.; Gray, K.M.; Wetherington, C.L.; McKee, S.A.; Allen, S.S. Determining menstrual phase in human biobehavioral research: A review with recommendations. Exp. Clin. Psychopharmacol. 2016, 24, 1-11. [CrossRef]

37. Straub, R.H. The complex role of estrogens in inflammation. Endocr. Rev. 2007, 28, 521-574. [CrossRef]

38. Angstwurm, M.W.A.; Gärtner, R.; Ziegler-Heitbrock, H.W.L. Cyclic plasma IL-6 levels during normal menstrual cycle. Cytokine 1997, 9, 370-374. [CrossRef]

39. Janský, L.; Reymanová, P.; Kopecký, J. Dynamics of Cytokine Production in Human Peripheral Blood Mononuclear Cells Stimulated by LPS or Infected by Borrelia. Physiol. Res. 2003, 52, 593-598. 